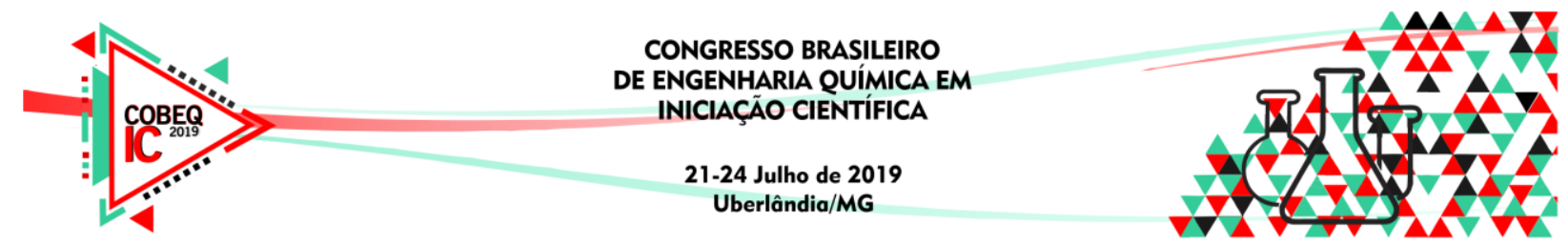

\title{
DESENVOLVIMENTO DE TRUFAS DE CACAU ENRIQUECIDA COM SMALLANTHUS SONCHIFOLIUS ATOMIZADO
}

\author{
G. J. R. SOUZA, J.C.C. SANTOS, P. S. CAMPOS, T.P.V.B. DIAS e L.F.OLIVEIRA \\ Universidade Federal de São João Del Rei, Laboratório de Bioquímica Metabólica e \\ Processos Biotecnológicos \\ grazielejrsouza@gmail.com
}

\begin{abstract}
RESUMO - O objetivo do presente estudo foi o desenvolvimento de um produto funcional, trufa de cacau com adição de pó de yacon atomizado em diferentes concentrações, sem adição de açúcar ou adoçantes sintéticos. A polpa de yacon foi triturada e filtrada em organza para obtenção do extrato. Adicionou-se goma arábica ao extrato para secagem em Spray dryer, obtendo o pó de yacon atomizado. Para a elaboração das trufas manteve-se as mesmas concentrações dos ingredientes base, trufa controle, e adicionaram-se diferentes porcentagens de pó de yacon atomizado nas trufas testes $(45$ e $90 \%)$. As trufas foram caracterizadas com relação: umidade, sólidos solúveis, $\mathrm{pH}$, acidez, compostos fenólicos e retenção de frutanos. As trufas obtiveram teor de umidade entre 11,75\% $\%$,65 e $11,82 \% \pm 0,65$, não havendo interferência da adição do pó de yacon. Houve um aumento dos frutanos $(8,55 \% \pm 0,42$ e $15,48 \% \pm 3,59)$ e, consequentemente, dos sólidos solúveis também $(11,11$ a $32,50 \%)$. O índice de acidez obteve um aumento proporcional ao aumento da concentração do pó de yacon sendo 2,46 \pm 0,22 da trufa de menor concentração $(45 \%)$ e 3,31 $\pm 0,03$ os valores para a trufa de maior concentração (90\%). Já os compostos fenólicos obtiveram valores 8,16 \pm $1,02 \mathrm{mg} \mathrm{GAE} / \mathrm{g}$ amostra, para trufa de $45 \%$ e $8,79 \pm 0,59 \mathrm{mg} \mathrm{GAE} / \mathrm{g}$ para trufa de $90 \%$.
\end{abstract}

\section{INTRODUÇÃO}

A busca do consumidor por uma dieta saudável e por alimentos funcionais vem crescendo cada dia mais, e nesse cenário o yacon (Smallanthus sonchifolius) destaca-se como um potencial promissor por ser fonte de frutanos, os quais possuem efeito hipoglicemiante, prebiótico e antioxidante conforme os trabalhos de Vanini et al. (2009) e Padla et al. (2012). Além dos seus efeitos fisiológicos os frutanos possuem alta qualidade sensorial e nutricional, o que o torna um excelente ingrediente para formulação de alimentos funcionais o que já foi descrito por Manrique et al. (2005) e Madrigal; Sangronis (2007).

O chocolate tipo amargo, devido a sua composição nutricional, é outro produto que está em alta no mercado, sendo fonte de substâncias fitoquímica, que promovem efeitos cardioprotetores e antioxidantes, reduzindo a incidência de neoplasias, diabetes mellitus, doenças gástricas e reumáticas de acordo com Souza, (2010). 


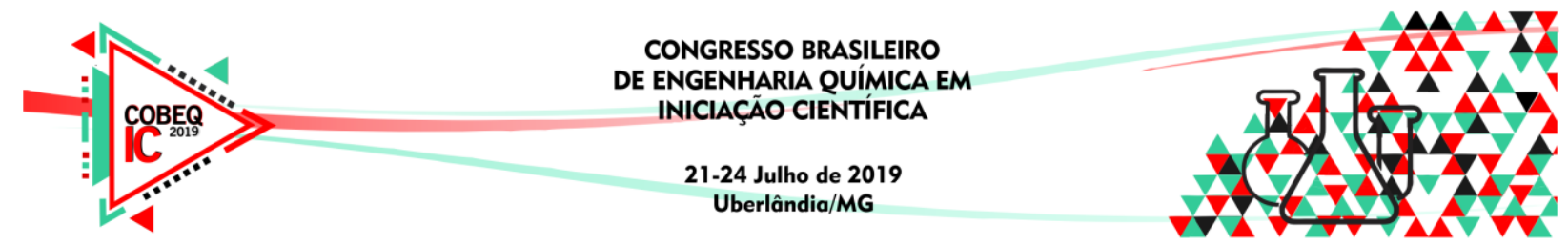

O yacon é um tubérculo de origem andina, normalmente consumido in natura devido sua textura e seu sabor adocicado e refrescante. Seu consumo ainda é limitado por ser um alimento um pouco mais caro que algumas frutas presentes no dia a dia e pelo desconhecimento do consumidor. Ele possui elevado teor de água e uma casca fina, o que facilita o surgimento de injúrias em seu transporte e manuseio, aumentando a oxidação de seus compostos e expondo ao crescimento microbiano conforme os trabalhos de Borges et al. (2012); Castro et al. (2012); Seminário \& Valderrama (2003).

Este trabalho objetivou o desenvolvimento de uma trufa de cacau com adição de pó de yacon atomizado em diferentes concentrações, sem adição de açúcar ou adoçantes sintéticos. Buscando um produto agradável ao paladar do consumidor e com características funcionais.

\section{METODOLOGIA EXPERIMENTAL}

\subsection{Preparo da Matéria Prima}

Os tubérculos de yacon (Smallanthus sonchifolius) e os ingredientes para as formulações da trufa foram obtidos no comércio local de Divinópolis - MG. Os yacons foram higienizados em água corrente para retirada de resíduos presentes e, em seguida descascados.

\subsection{Preparo do pó atomizado da polpa de yacon}

A preparação do extrato aquoso da polpa de yacon para secagem em Spray Dryer foi realizado conforme Nish (2012). Fatias de yacon foram trituradas com 0,03\% de bissulfito de sódio, com relação aos sólidos totais, durante 2 minutos. A solução obtida foi filtrada com auxílio de uma organza. A solução filtrada adicionou-se o adjuvante, goma arábica, na concentração de 38,20\% em relação aos sólidos totais do extrato, conforme Chagas e colaboradores (2016). A solução permaneceu sob agitação por 30 minutos para a aderência da goma ao extrato de yacon. A secagem por atomização da solução foi realizada em Mini Spray dryer modelo MSDi 1.0 Labmaq, fixando os seguintes parâmetros: bico atomizador de 1,0 mm de diâmetro, uma vazão de alimentação do secador de $0,6 \mathrm{~L} / \mathrm{h}$, pressão de ar comprimido de $3,5 \mathrm{kgf} / \mathrm{cm}^{2}$, vazão do ar de atomização de $40,5 \mathrm{~L} / \mathrm{min}$ e temperatura de $139^{\circ} \mathrm{C}$ de acordo com Chagas et al. (2016).

\subsection{Preparo da trufa de cacau com adição de yacon atomizado}

Para o desenvolvimento da trufa de cacau com pó de yacon atomizado foram realizadas diferentes formulações, tendo como ingredientes bases, chocolate em pó $100 \%$ cacau, creme de leite sem lactose e manteiga, e variando apenas a concentração de pó de yacon atomizado, $45 \%$ e $90 \%$ com relação aos ingredientes base. Para uma melhor comparação também foi desenvolvida uma trufa sem a adição de pó de yacon atomizado, trufa controle.

\subsection{Caracterização das trufas}

As trufas foram caracterizadas com relação à umidade, $\mathrm{pH}$, acidez, compostos fenólicos e teor de frutanos. Todas as análises foram realizadas em triplicata. O teor total de umidade (U $\%$ ) foi determinado de acordo com metodologia proposta pela AOAC (1997), método 


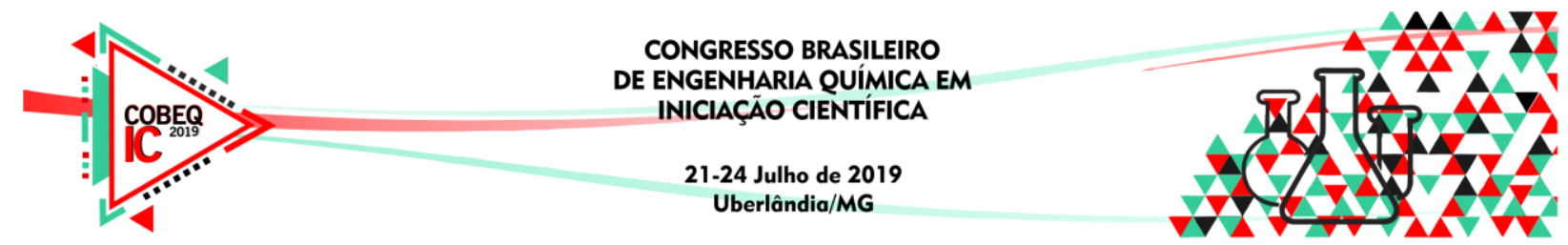

gravimétrico modificado, onde $1 \mathrm{~g}$ da amostra foi pesada em placa de petri em balança semianalítica e em seguida as placas contendo a amostra foram levadas em estufa ao vácuo a $70^{\circ} \mathrm{C}$ e pressão reduzida $<100 \mathrm{mmHg}$, até peso constante. A porcentagem de umidade foi determinada conforme a Equação 1:

$$
U(\%)=\left[\frac{\text { peso da amostra inicial }- \text { peso da amostra final }}{\text { peso da amostra inicial }}\right] \times 100
$$

A medida de $\mathrm{pH}$ foi avaliada por meio de pHmetro digital modelo mPA-210 Ávila Científica, devidamente calibrado com soluções-tampão com pH 4 e 7.

Os teores de sólidos solúveis foram determinados por leitura direta em refratômetro modelo RTD-95 Instrutherm e expressa em ${ }^{\circ}$ Brix.

A determinação do índice de acidez foi segundo procedimento descrito pela AOCS (1997) modificado para as diluições. Para a análise, pesou-se $0,25 \mathrm{~g}$ da amostra em um erlenmeyer, adicionou $12,5 \mathrm{~mL}$ de álcool etílico $95 \%$ e 2 gotas de fenolftaleína $1 \%$. A amostra foi então titulada com hidróxido de sódio $0,1 \mathrm{~N}$ até o aparecimento da cor rósea, relativo ao ponto de viragem. Para os cálculos do índice de acidez, expresso em \% de ácidos graxos livres, aplicou-se a Equação 2:

Indice de acidez $=\frac{\text { volumegasto de } \mathrm{NAOH} \times 0,1 \mathrm{~N} \times 28,2}{\text { Massa de amostra }(g)}$

O conteúdo de compostos fenólicos totais foi determinado pelo método de FolinCiocalteau, segundo metodologia descrita por Singleto e colaboradores (1999) modificada.

Para a determinação do teor de frutanos realizou-se a diferença entre açúcares totais e açúcares redutores, conforme Arrizon e colaboradores (2010). Os frutanos são polímeros de frutose, sendo açucares não redutores, a frutose já é um monossacarídeo considerado açúcar redutor. Como quantificamos os açúcares totais e os açúcares redutores, a diferença entre eles pode ser considerada como açúcares não redutores, os frutanos.

A quantificação de açúcares totais foi determinada através da reação de Antrona, modificada especificamente para cetoses conforme Jermyn (1956), utilizando como padrão a frutose: adicionou $60 \mu \mathrm{L}$ da trufa, previamente diluída, $100 \mu \mathrm{L}$ de água deionizada e $2,5 \mathrm{~mL}$ de reagente Antrona. Agitou-se e levou em banho-maria a $37^{\circ} \mathrm{C}$ por 45 minutos, resfriou em banho de gelo. Realizou a leitura da absorbância a $620 \mathrm{~nm}$.

Os açúcares redutores foram determinados usando o reagente ácido 3,5-dinitrosalicico (DNS), utilizando glicose como padrão: adicionou $0,8 \mathrm{~mL}$ da trufa, previamente diluída, 1,4 $\mathrm{mL}$ de água deionizada e $2,0 \mathrm{~mL}$ de reagente DNS. Agitou-se e levou em banho-maria a $100^{\circ} \mathrm{C}$ por 6 minutos. Após resfriado em banho de gelo, realizou-se a leitura da absorbância a $540 \mathrm{~nm}$.

\subsection{Analise estatística}




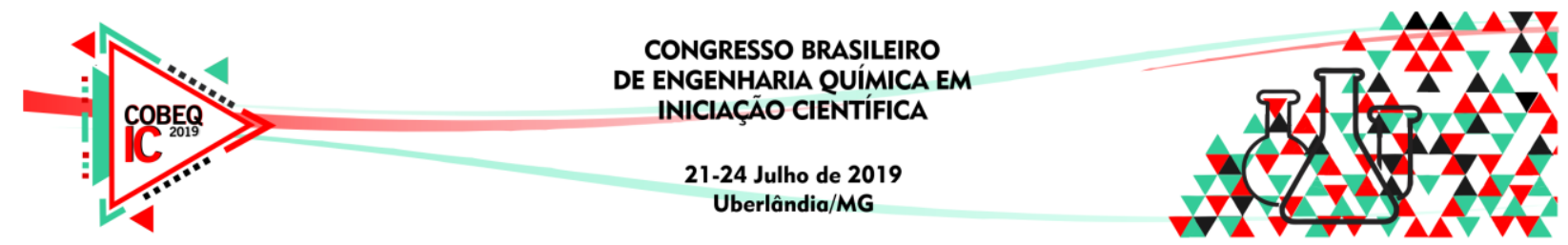

Os resultados obtidos foram apresentados como média \pm desvio padrão, realizando-se a análise de variância (ANOVA) dos dados. O Teste de Tuckey foi aplicado para os resultados que apresentaram diferença significativa, afim de comparação das médias, com auxílio do software Statistica Versão 8.0 (STATISTICA, 2008).

\section{RESULTADO E DISCUSSÃO}

Pelo teste de ANOVA, observou-se que a umidade, os compostos fenólicos (CF) e pH não diferem estatisticamente em relação as concentrações de pó de yacon adicionadas ( $>0,05)$. As respostas para teor de frutanos, sólidos solúveis (SS) e índice de acidez foram estatisticamente significativas ( $\mathrm{p}$-valor $<0,05$ ), obtendo valores de f-calculado maiores que o f-tabelado $(5,14)$, comprovando o bom ajuste da regressão, assim, o teste de Tukey foi utilizado para análise do efeito da adição de diferentes concentrações de pó de yacon sobre as respostas médias (Tabela 1 ).

Tabela 1 - Média \pm DP e Teste de Tukey das respostas umidade, compostos fenólicos, frutanos, sólidos solúveis, $\mathrm{pH}$ e índice de acidez

\begin{tabular}{ccccccc}
\hline Trufas & U\% & $\begin{array}{c}\text { CF (mgGAE/g } \\
\text { amostra) }\end{array}$ & pH & S.S & Frutanos\% & Acidez \\
\hline Controle & $11,75 \pm 0,65$ & $7,79 \pm 0,10$ & $6,76 \pm 0,00$ & $10,20 \pm 0^{\mathrm{a}}$ & $0^{\mathrm{a}}$ & $1,46 \pm 0,62^{\mathrm{a}}$ \\
& & & & & & \\
$\mathbf{4 5 \%}$ & $12,74 \pm 1,15$ & $8,16 \pm 1,02$ & $6,82 \pm 0,04$ & $22,22 \pm 3,1^{\mathrm{b}}$ & $8,55 \pm 0,41^{\mathrm{b}}$ & $2,46 \pm 0,22^{\mathrm{b}}$ \\
$\mathbf{9 0 \%}$ & $11,82 \pm 0,65$ & $8,78 \pm 0,59$ & $6,73 \pm 0,04$ & $32,5 \pm 2,5^{\mathrm{c}}$ & $15,47 \pm 3,58^{\mathrm{c}}$ & $3,31 \pm 0,03^{\mathrm{b}}$ \\
\hline
\end{tabular}

Diferentes letras em uma mesma coluna diferem entre si significativamente, $\mathrm{p}$-valor $<0,05 \%$.

O pó de yacon não interferiu no teor de umidade das trufas, sendo um bom indicativo, pois, o teor de umidade nas trufas é de grande importância, uma vez que determina a vida de prateleira do produto, evitando o crescimento de microrganismo e sendo intimamente relacionado com as propriedades da textura de acordo com Aidoo et al. (2014). A legislação brasileira, no que diz a respeito da umidade de bombons e similares, não estipula limites para estes valores (Reis, 2011).

A não interferência significativa da adição de yacon na trufa no teor de $\mathrm{CF}$, também foi observado por Belscak-Cvitanovic (2015), que, ao analisar os compostos fenólicos em chocolates com açucares reduzidos, relatou que o uso de ingredientes naturais como fonte de edulcorantes, mesmo sendo carreadores de CF, não aumentaram os teores de CF dos chocolates produzidos quando comparado ao chocolate tradicional, produzido com sacarose.

Os teores de sólidos solúveis incluem importantes compostos responsáveis pelo sabor, esse teor são o total de todos os sólidos dissolvidos em água, incluindo proteínas, óleos essenciais, aminoácidos livres, ácidos e, principalmente, açúcares. Houve um aumento dos sólidos solúveis com o aumento da concentração do pó de yacon (Tabela1), assim como 


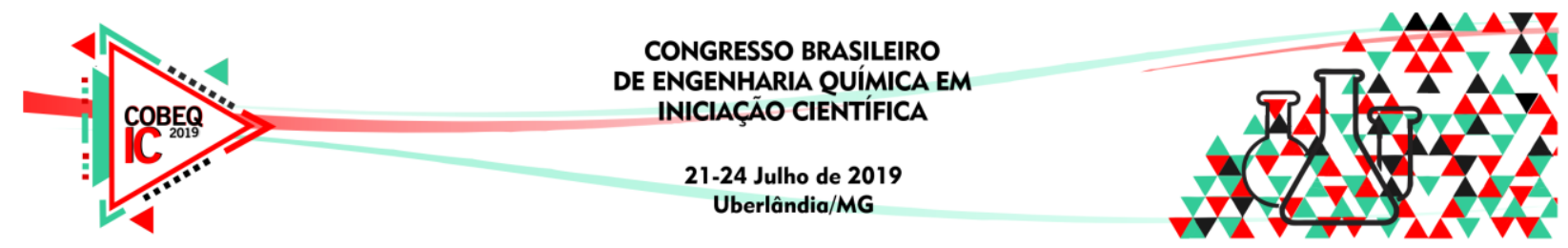

ocorreu com o teor de frutanos. Ao analisar a concentração de sólidos solúveis presente em geleia de mel de cacau sem adição de açúcar foi encontrado uma média de $44^{\circ}$ Brix conforme Santos (2012).

De acordo com a legislação considera alimentos com alegação funcional aqueles que apresentarem no mínimo $3 \mathrm{~g}$ de FOS, para alimento sólido por porção do produto para consumo, Brasil (2018), sendo que a porção para chocolates, bombons e similares equivale a $25 \mathrm{~g}$. Ou seja, seriam necessários no mínimo $12 \%$ de teor de frutanos nas trufas. Ao analisar a formulação da trufa de $90 \%$ de pó de yacon verifica-se que o valor encontrado $(15,47 \%)$ de frutanos torna a trufa um alimento funcional diante a ANVISA.

\section{CONSIDERAÇÕES FINAIS}

Conclui-se que as diferentes concentrações de pó de yacon atomizado estudadas não interferiram no teor de compostos fenólicos. Com as novas formulações, o aumento das concentrações de yacon provocaram um aumento no teor de frutanos e sólidos solúveis.

O objetivo desse trabalho era o desenvolvimento de uma trufa de cacau com adição de pó de yacon atomizado em diferentes concentrações, sem adição de açúcar ou adoçantes sintéticos, buscando um produto de fácil consumo, enriquecido nutricionalmente e adoçado por um produto natural, o objetivo foi alcançando, obtendo trufas enriquecidas nutricionalmente com frutanos, podendo ser consumidas por um público com restrição ao consumo de açúcar. Com a adição de $90 \%$ do pó de yacon foi possível chegar à alegação de um alimento funcional.

\section{REFERÊNCIAS BIBLIOGRÁFICAS}

AIDOO, R. P.; AFOAKWA, E. O.; DEWETTINCK, K. Optimization of inulin and polydextrose mixtures as sucrose replacers during sugar-free chocolate manufacture Rheological, microstructure and physical quality characteristics. Journal of Food Engineering. v.126, p.35-42, 2014.

AOAC - ASSOCIATION OF OFFICIAL ANALYTICAL CHEMISTS. Official Methods of Analysis, 16th Ed., Washington, DC: AOAC,1997.

ARRIZON, J. et al. Comparison of the water-soluble carbohydrate composition and fructan structures of Agave tequilana plants of different ages. Food Chem., v. 122, p.123-130, 2010 .

BESCAK-CVITANOVIC, A. Physical, bioactive and sensory quality parameters of reduced sugar chocolates formulated with natural sweeteners as sucrose alternatives. Food Chemistry. v.167, p.61-70, 2015.

BRASIL. Agência Nacional de Vigilância Sanitária. Alimentos com Alegações de Propriedades Funcionais e ou de Saúde, Novos Alimentos/Ingredientes, Substâncias Bioativas e Probióticos. Disponível em: < http://www.anvisa.gov.br/alimentos/comissoes/tecno_lista_alega.htm > Acessado em: 03 de Agosto de 2018. 


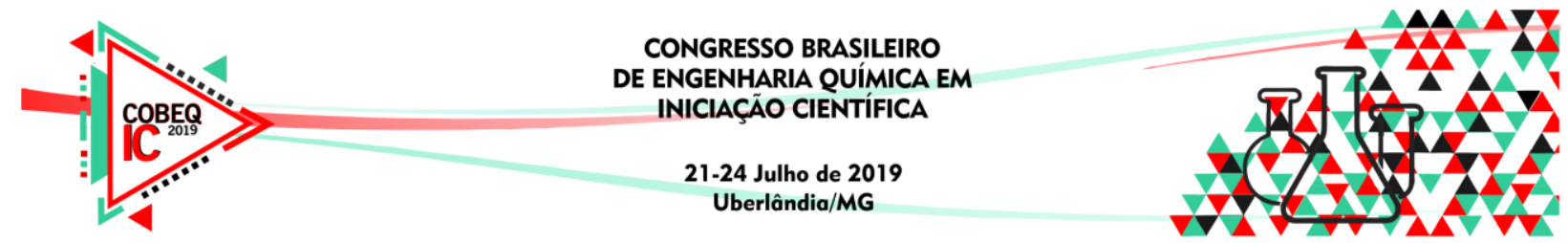

BORGES, J. T. da S. et al. Yacon na alimentação humana: Aspectos nutricionais, funcionais, utilização e toxicidade. Scientia Amazonia, 1 (3), p. 3-16, 2012.

CHAGAS, V. S. et al. Avaliação da influência da temperatura e da concentração de Adjuvante no teor de frutanos na secagem por atomização da polpa de yacon (Smallanthus sonchifolius). In XXI Congresso Brasileiro de Engenharia Química e XVI Encontro Brasileiro sobre o Ensino de Engenharia Química, 2016.

JERMYN, M. A. A new method for determination of ketohexose in presence of aldohexoses Nature (Paris), v.177, p.38, 1956.

MADRIGAL, L.; SANGRONIS, E. La inulina y derivados como ingredientes claves en alimentos funcionales. Archivos Latinoamericanos de Nutrición, v. 57, n. 4, p. 387-396, 2007.

NISHI, A. C. F. Extrato aquoso de yacon (Smallanthus sonchifolius) desidratado por atomização. 2012. 84f. Dissertação (Mestrado em Nutrição e Saúde) - Programa de Pósgraduação em Nutrição e Saúde, Universidade Federal de Goiás, Goiânia, 2012.

REIS, E. C. Análise fisico-química e microbiológica de bombons artesanais. 36f. Trabalho de conclusão de curso em Tecnologia em Processos Químicos, Universidade Tecnológica Federal do Paraná, Apucarana, 2011.

SANTOS, C. O. Aproveitamento industrial de "mel" de cacau (Theobroma cacao 1) na produção de geléia sem adição de açùcar. 92f. Dissertação (Mestrado em Ciência de Alimentos) - Programa de Pós-graduação em Ciência de Alimentos, Universidade Federal da Bahia, Salvador, 2012.

SEMINARIO, J.; VALDERRAMA, M. El yacon: fundamentos para el aprovechamiento de un recurso promisorio. Lima, Peru: Centro Internacional de la Papa (CIP), Universidad Nacional de Cajamarca, Agencia Suiza para el Desarrollo y la Cooperación (COSUDE), 2003. 60p. Acesso em 20 mar. 2019. Online. Disponível na Internet http://www.cipotato.org/market/PDFdocs/ Yacon_Fundamentos_password.pdf.

SINGLETON, V. L; ORTHOFER, R; RAVENTOS, R. M. L. Analysis of total phenols and other oxidation substrates and antioxidants by means of folin-ciocalteu reagent. Methods in enzymology. v.199, p 152-178, 1999.

SOUZA, A. S. L. Avaliação da estabilidade térmica e oxidativa de chocolates amargos. João Pessoa, 2010. 110f. Dissertação (Mestrado em Ciência e Tecnologia de Alimentos) Programa de Pós-graduação em Ciência e Tecnologia de Alimentos, Universidade Federal da Paraíba, João Pessoa, 2010.

STATISTICA. DATA ANALYSIS SOFTWARE SYSTEM, V.8.0, STAT-SOFT, INC., USA. 2008. Disponível em: < www.statsoft.com>

VANINI, M. et al. A relação do tubérculo andino yacon com a saúde humana. Ciênc. cuid. saúde, 8, p. 92-96, 2009. 